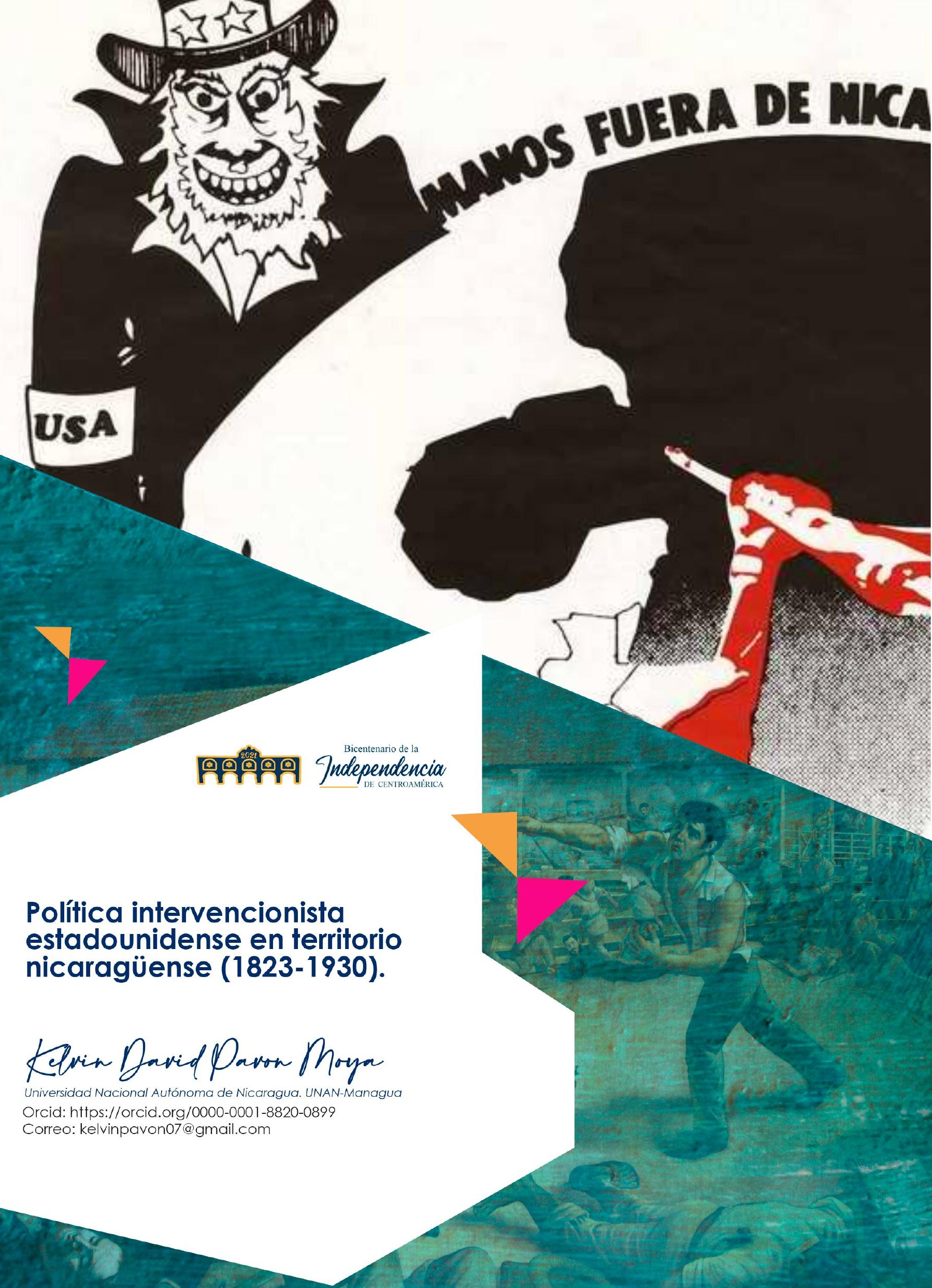




\section{Política intervencionista estadounidense en territorio nicaragüense (1823-1930)}

US interventionist policy in Nicaraguan territory (1823-1930)

\section{RESUMEN}

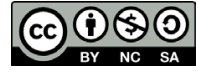

Copyright $\odot 2021$ UNAN-Managua Todos los DerechosReservados.
Recibido: 22 julio 2021

Aprobado: 30 agosto 2021

La motivación que ha llevado a la elaboración de este trabajo es la reflexión tras el impacto ignominioso de políticas promovidas desde Washington hacia Nicaragua, que ha repercutido en la vida social de sus habitantes. El presente artículo versa sobre las relaciones de carácter diplomático, histórico, militar y político entre la nación estadounidense y nicaragüense, ofreciendo una profunda visión analítica de los hechos de mayor impacto en la sociedad nacional, proponiendo que dichas relaciones están inmersas en un ciclo de intervencionismo norteamericano bajo el radar del interés filosófico y expansionista que se inició con el Doctrina Monroe, que con el pasar de las décadas se manifestará en estrategias bilaterales que desencadenarán con el ascenso presidencial de Anastasio Somoza García.

\section{ABSTRACT}

The motivation that has led to the elaboration of this work is the reflection after the ignominious impact of policies promoted from Washington towards Nicaragua, which has had repercussions in the social life of its inhabitants. This article deals with the diplomatic, historical, military and political relations between the United States and Nicaragua, offering a deep analytical vision of the facts of greater impact on the national society, proposing that these relations are immersed in a cycle of American interventionism under the radar of the philosophical and expansionist interest that began with the Monroe Doctrine, which over the decades will manifest itself in bilateral strategies that will trigger with the presidential rise of Anastasio Somoza Garcia. must be highlighted in national history as a hero who He was at the forefront of the struggles for independence.

\section{PALABRAS CLAVE \\ Intervención, Guerra Nacional, \\ Filibusteros, Geoestrategia, Pactos Dawson, Caudillo, Oligarquía, Guardia Nacional.}

\section{KEYWORDS}

Intervention, National War, Filibusters, Geostrategy, Dawson Pacts, Caudillo, Oligarchy, National Guard

\section{Introducción.}

La investigación ha sido realizada bajo el enfoque cualitativo, que consiste en estudiar la realidad en su contexto natural y cómo sucede, a través de la lectura, fichaje y el análisis de diversas fuentes académicas y científicas, disponibles tanto en fuentes bibliográficas como recursos en la red; se visitó la Biblioteca Central Salomón de Selva, así como sitios virtuales: Repositorio Académico de la Universidad Centroamericana, Digitalia, Academia.edu, Dialnet. El método empleado en este trabajo es histórico lógico y deductivo porque mediante este proceso se permitió presentar conceptos, reglas, principios definiciones a partir de las cuales, se sintetiza compara, generaliza y demuestra de manera cronológica y contextual. La técnica empleada es documental, lo cual tras la búsqueda y fichaje permitió la recopilación de información para enunciar las teorías que sustentan el estudio de los fenómenos y procesos referidos al tema. 
Contexto histórico de las relaciones internacionales de Nicaragua con Estados Unidos $(\mathrm{XIX}-\mathrm{XX})$

La independencia y autodeterminación de los pueblos es un derecho inalienable, pero desde finales del siglo XIX y a lo largo del XX el gobierno de los Estados Unidos ha usado diversas estrategias de intromisión en gran parte del hemisferio occidental, de manera especial contra Nicaragua.

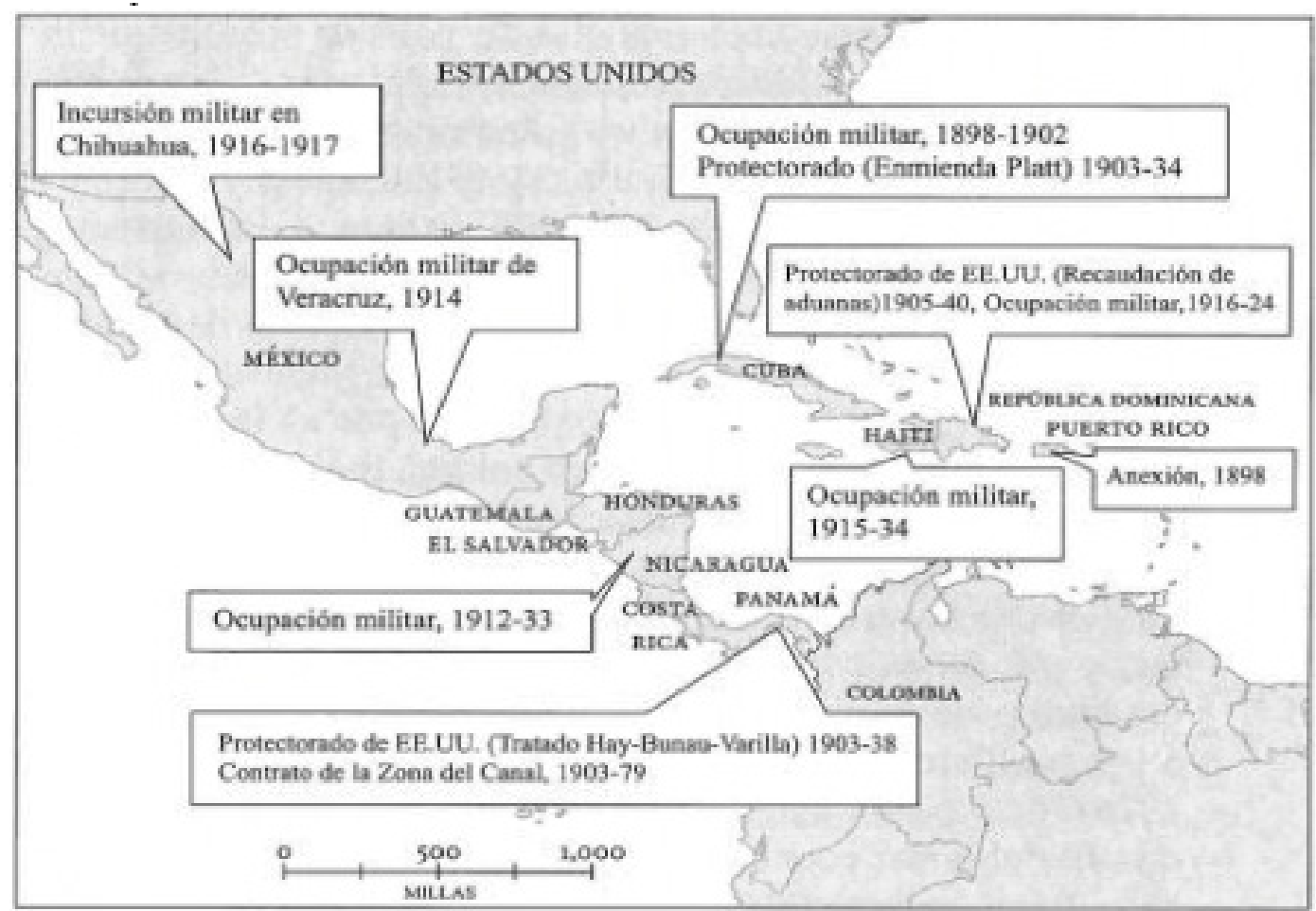

Principales intervenciones de los EEUU en Centroamérica y El Caribe durante el siglo XIX y XX. Gobat, M. (2010). Enfrentando el Sueño Americano. Mapa 2. Recuperado de http://repositorio.uca.edu.ni/3315/1/Enfrentando\%20el\%20sue\%C3\%B10\%20americano.

Es innegable que América Latina ha sido históricamente un foco de interés para los Estados Unidos por su valor geopolítico, económico y estratégico dado los abundantes recursos naturales que tienen estas tierras para ser explotados, y que por ello a partir del siglo XIX la política exterior estadounidense se ha visto marcada por un largo proceso expansionista, el que, como afirma (Navas- J et al:2016; 2). "se apoya ideológicamente en el "mesianismo" característico del destino manifiesto y políticamente en la conocida doctrina Monroe del año 1823, "América para los americanos". La que a su vez desembocó en la política del Big Stick (Gran garrote) del republicano Theodore Roosevelt (1901-1909).

La Doctrina Monroe en 1823, sentó las bases para lo que ha sido una larga cadena de injerencias en los asuntos internos de los países de América Latina y del Caribe, enunciada inicialmente por el entonces presidente de los Estados Unidos, James Monroe, en respuesta a la amenaza que suponía la restauración monárquica en Europa y la Santa Alianza, la que se sintetizó posteriormente en la conocida fórmula "América para los americanos". 
El ideario popular de la doctrina Monroe no solo pretendía frenar el expansionismo europeo en América, sino también crear sistemas económicos dependientes de Estados Unidos en nuestros países. Como afirma (Guzmán: 2005; 4). "La doctrina Monroe fue el primer paso ideológico con el que Estados Unidos enfrentaba a los ingleses y por ende hacía caer a América Latina bajo su dominio". Pues se debe recordar que, aunque América Latina consiguió su independencia su sistema económico siguió siendo débil y dependiente, por lo que tuvo que adherirse a las reglas del juego que imponían primero Inglaterra y posteriormente Estados Unidos.

El Destino Manifiesto fue otra maniobra filosófica y religiosa con la que los estadounidenses se arrogaban el derecho del expansionismo como "voluntad de Dios que no debe ser impedida por nadie". Recurriendo a un viejo aforismo de Juan Calvino, padre de los puritanos que se asentaron en los Estados Unidos, los gobernantes de este país aseguraban que esa nación estaba predestinada por Dios a expandirse por toda América, de modo que debían combatir a quienes se opusieran a esa voluntad divina.

En este sentido (Barreto: 2012; 14). Plantea que "desde ese nivel supraestructural Estados Unidos ha invadido países argumentando razones absurdas como que eran "pueblos inferiores" o que habia que "civilizarlos" $y$ "evangelizarlos" como sucedió con México en 1847 para despojarlos de más de la mitad de su territorio". Situación que se evidencia en Nicaragua desde el momento en que la ocupación estadounidense se asentó en este país desde mediados del siglo XIX.

A partir de los años 40 del siglo XIX los norteamericanos se beneficiaban de este país por medio de sus viajes a través del río San Juan y el gran Lago de Nicaragua transportando carga y pasajeros estadounidenses que iban desde la Costa Caribe a California en busca de oro. Es importante recordar que en este contexto la fiebre del oro californiano convierte a Nicaragua en una de las principales rutas de tránsito para los estadounidenses.

No obstante, como bien plantea (Granados: 1985; 21) "su importancia no está dada sólo por los recursos que este país posee sino por su situación geográfica y lo vital que esto resulta para la circulación interna y externa de sus mercancías". Este hecho aclara el verdadero interés de los Estados Unidos en Nicaragua desde inicios del siglo XIX: La construcción de un canal interoceánico que le permita transportar en menor tiempo y a bajo costo todas sus mercancías de un extremo del país al otro.

La idea de construir un canal que comunicara los océanos Atlántico y Pacífico fue de mucho interés para los círculos de poder en Estados Unidos y ocupó un lugar de primer orden en la política exterior de este país desde inicios del siglo XIX. Así como crecían económicamente también proliferaba el apetito voraz y agresivo con que condujeron sus planes para eliminar o por lo menos neutralizar la oposición de un rival tan poderoso como Inglaterra.

En Nicaragua este proyecto fue percibido por la élite nacional como una gran oportunidad para colocar al país en la ruta del progreso y la prosperidad teniendo como ejemplo inspirador al propio Estados Unidos. En este sentido, (Jaúregi: 2015; 11) considera que "este sector social percibia a los Estados Unidos como un paradigma de progreso económico y vigor nacional, más que un modelo de libertad política". Tal situación facilitó las posteriores acciones entreguistas de la oligarquía nicaragüense. 
El esfuerzo persistente de Inglaterra por tener control en toda el área del futuro canal obligó a la diplomacia norteamericana a buscar un acuerdo especial con los ingleses. Este acuerdo se firmó el 19 de abril de 1850 y garantizaba conjuntamente la neutralidad y el carácter internacional del canal sin que nadie recibiera ninguna ventaja exclusiva. Las negociaciones estuvieron a cargo del Secretario de Estado de los Estados Unidos John Clayton y Sir Henry Lytton Bulwer, Embajador inglés en Washington. Sin embargo, como bien afirma (Guzmán: 2005; 17) "este tratado benefició más a los capitalistas estadounidenses porque reducian la influencia de Inglaterra en estas zonas y creaban otra oportunidad para construir el canal de manera exclusiva: en Panamá".

Mientras tanto, en Nicaragua, la permanente guerra por alcanzar el poder político de los partidos establecidos, llamados entonces "Timbucos y Calandracas" fue aprovechada de inmediato por los estadounidenses cuando los democráticos de León contratan a un grupo de mercenarios, conocidos como "filibusteros" para vencer en la Guerra Nacional a los conservadores. Este grupo armado trae como su jefe al señor Byron Cole que dentro de sus leales aliados está William Walker, siendo este último quien tomó mayor protagonismo en la escena nacional.

Walker, un ambicioso médico, abogado y periodista estadounidense se aprovecha de la división política que vivía Nicaragua y luego de ganar la simpatía de los democráticos por las victorias contra los conservadores asciende rápidamente en popularidad y empieza a sembrar el terror provocando la emigración masiva a otros países de Centroamérica, a tal punto que se rebela contra sus primeros patrocinadores y aliados, los democráticos, y se autoproclama Presidente de Nicaragua, el 12 de julio de 1856. (Granados: 1985; 34) considera que "la guerra civil en Nicaragua puso a Walker en la mejor posición para emprender la americanización de esta República". Pues apenas llegó al poder empezó a fusilar a sus adversarios, a desafiar a gobiernos vecinos y a rebelarse a sus antiguos aliados, los democráticos.

La presión de los gobiernos centroamericanos y el descontento que manifiestan ambos partidos en Nicaragua por las atrocidades de Walker los obligan a unirse para combatir a los filibusteros. Esto marca el inicio de una lucha por lo que podría llamarse una segunda independencia. Es así como luego de que democráticos y legitimistas discutieron diversas formas de arreglo, llegaron a la proposición de un solo gobierno para toda la República presidido por don Patricio Rivas. El 12 de septiembre de 1856 mediante un convenio se alcanzó la unidad de los nicaragüenses en contra de los filibusteros.

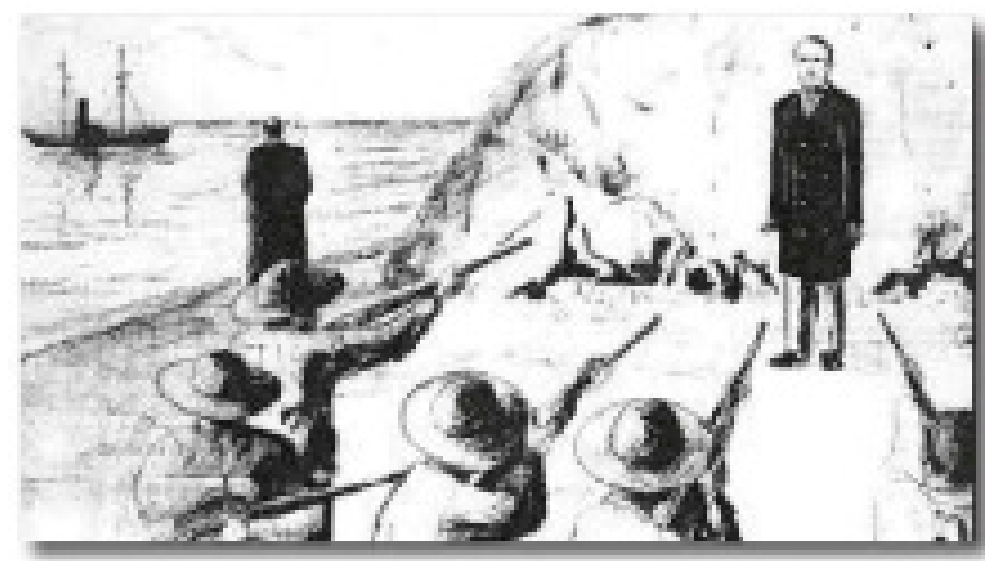

Walker fusilado en trujillo. Honduras 12 de Septiembre 1860. 
El primer bastión de esa lucha fue la Hacienda San Jacinto ocupada por el General José Dolores Estrada. El 14 de septiembre de 1856 se registró una batalla que significó la primera derrota para los filibusteros. El combate se decidió a favor de los patriotas nicaragüenses después de que un grupo de indios flecheros, provenientes de Matagalpa, salió a flanquear a los filibusteros y los acorraló desde la retaguardia. Según relata (Granados: 1985; 41) "el coronel Byron Cole, fundador del filibusterismo y jefe de la fracasada expedición, fue apresado por unos campesinos del lugar, quienes le dieron muerte inmediatamente".

Después de 4 días de combates en Masaya las tropas filibusteras se retiran a Granada y resuelven incendiarla. La tarea le es encomendada al General Carlos F Henningsen, quien sale huyendo, pero deja un mensaje lapidario en el centro de la ciudad: Aquí fue Granada. No obstante, nuevos combates contra los filibusteros desmoralizan a los invasores y William Walker se rinde y firma un compromiso de no regresar a ningún país de Centroamérica. Hecho que no cumple porque el 6 de agosto de 1860 desembarcó en Trujillo, Honduras, pero es detenido y fusilado en ese mismo lugar.

En 1857, al finalizar la Guerra Nacional, Máximo Jerez y Tomás Martínez suscribieron un acuerdo político que dio lugar a un gobierno bipartidista de transición y a la posterior puesta en vigencia de la Constitución de 1858, que proporcionó el marco jurídico para emprender la tarea de organizar el Estado nicaragüense.

La élite política nicaragüense coincidía en torno a la idea de que era necesario consolidar las instituciones del Estado, extender su radio de acción a todo el territorio, y aumentar su poder coercitivo para imponer el orden y alcanzar el progreso. La normalidad fue interrumpida por el levantamiento del militar liberal José Santos Zelaya, que puso fin en 1893 a las tres décadas de dominio conservador.

La Revolución liberal que lideró Santos Zelaya modernizó el Estado de Nicaragua mediante la promulgación de una nueva Constitución a la cual llamó "La Libérrima". De acuerdo con (Esgueva: 2009; 23) "esta Constitución propiciaba con decisión la unión centroamericana y facultaba al ejecutivo a buscarla por todos los medios necesarios". Además, significó un avance sin paralelos en lo que respecta a la vida social de los nicaragüenses porque abolió la esclavitud, estableció la gratuidad de la educación, estableció un Estado laico, abolió la pena de muerte, instauró la libertad de prensa, impuso el matrimonio civil como antesala del matrimonio religioso, impuso la libertad de culto, libertad económica, libertad de enseñanza y respeto a la propiedad privada. Pero, sobre todo, mantuvo una posición de independencia y autodeterminación frente a las prácticas injerencistas de los Estados Unidos que indudablemente enojaron al gobierno norteamericano de aquel momento.

Para entonces, Estados Unidos, continuaba en su afán de construir el canal interoceánico antes mencionado, retoma la iniciativa del mismo y propone al gobierno de Zelaya su construcción, pero este se niega a que todo el capital sea administrado única y exclusivamente por Estados Unidos. Como la idea del canal se vuelve obsesiva para los americanos estos ponen su mirada en Panamá y le plantean al gobierno colombiano, del cual Panamá era una provincia, la construcción del mismo. Pero este rechaza el proyecto.

Ansiosos por la construcción del canal los Estados Unidos apoyaron un movimiento independentista panameño y así el 03 de noviembre de 1903 Panamá obtuvo su independencia y Estados Unidos adquirió en recompensa por su apoyo, la soberanía del futuro canal, el cual fue inaugurado el 15 de agosto de 1914. 
Sin embargo, como aún se mantenía latente en Nicaragua la idea del canal y el presidente Zelaya gestionaba con potencias europeas el capital para su construcción Estados Unidos volvió a la carga y usó la excusa del fusilamiento de dos norteamericanos que fueron descubiertos infraganti minando dos puertos en San Juan del Norte, el ingeniero Lee Roy Cannon y el experto en explosivos Leonard Grace, para obligar a Zelaya a dimitir, mediante una nota enviada por Philander Nox, Secretario de Estado de Estados Unidos. Hecho que según (Cajina: 2010; 11) es considerado como "la máxima expresión de la prepotencia imperial y el intervencionismo de la época". Todo esto en medio de la promulgación de la política del Gran garrote, mediante la cual, según (Cánovas: 2010; 23) "Se aplicaría el uso de la fuerza contra los países que se negaran a aceptar sus ofertas "generosas".

(Bolaños: 2007; 14) explica que "la salida de Zelaya no redujo los enfrentamientos por el poder de las élites nicaragüenses ni tampoco el interés de Estados Unidos por aumentar sus esferas de influencia en el país". De hecho, tras la renuncia de Zelaya el plan que los Estados Unidos puso entonces en marcha fue reducir a Nicaragua a la situación de simple colonia, gobernada por presidentes títeres e intervenida en todos los aspectos, con la complicidad de los grupos políticos conservadores ahora de nuevo en el poder.

En esas circunstancias el gobierno estadounidense envía a su ministro Tomas Dawson para decirle al nuevo gobierno de Juan José Estrada y Adolfo Díaz que su reconocimiento por parte de Estados Unidos tiene dos condiciones: realizar un préstamo a Estados Unidos poniendo como garantías El Banco Nacional, las aduanas y el ferrocarril y permitir la permanencia en nuestro país de los marines yanquis para garantizar "el orden".

El resultado de esta misión es la firma de los "pactos Dawson" la cual puso en práctica la nueva "Diplomacia del Dólar" con la que el imperialismo yanqui podía mantener subyugados a los pueblos. Estos pactos confirman, como dice (Rodríguez: 2014; 33) que "Nicaragua fue uno de los primeros ensayos del neocolonialismo norteamericano".

La situación del país no podía ser peor, los índices de pobreza incrementaban de forma galopante mientras las fortunas de los gringos y los oligarcas criollos se acrecentaban. En medio de este descontento Benjamín Zeledón, un abogado y militar jinotegano se suma a la lucha del general Luis Mena, contra las maniobras entreguistas del gobierno de Adolfo Díaz.

El General Zeledón muere combatiendo contra los invasores gringos y con esto se pone de manifiesto la doctrina del Big Stick o El gran garrote de la que ya se ha tratado en este artículo y como bien afirma " $L a$ intervención de las fuerzas norteamericanas bajo la política del "gran garrote" en nuestros asuntos internos, ha lesionado en muchas ocasiones nuestra soberanía”.

El 4 de octubre de 1912, el propio día de su cumpleaños, después de haber sido gravemente herido por fuerzas del gobierno de Adolfo Díaz Recinos, Benjamín Zeledón fue arrastrado por sus enemigos en una carreta, le negaron el tiro de gracia que pedía y dieron órdenes para que se le dejara desangrar hasta su muerte.

En la misma carreta lo llevaron a enterrar a Catarina. Al pasar por Niquinohomo un joven de 17 años miró el cadáver de Zeledón, aquel joven se llamaba Augusto C. Sandino, quien más tarde diría: "Vi que pasaba el cadáver del pueblo asesinado." 
(Ramírez: 1983; 38) afirma categóricamente que "Benjamín Zeledón fue el primer ciudadano del siglo XIX, que sabiendo que iba hacia la muerte, lanzó su protesta armada contra el ultraje del invasor yanqui, salvando con su sangre y la de sus compañeros, el honor de Nicaragua en 1912." Esta cita remarca el valor que tuvieron algunos patriotas para enfrentar el intervencionismo estadounidense en nuestro país.

Los grandes beneficiarios de los pactos Dawson fueron los banqueros del consorcio de Nueva York, ellos llegaron a controlar los ferrocarriles, los vapores del Gran Lago, el Banco Nacional, recogieron el producto de las aduanas y llamaron a la fuerza militar de los Estados Unidos para controlar cualquier estallido social por sus abusos.

El 8 de febrero de 1913 el General Emiliano Chamorro firmó con George Weitzel, un tratado que (Romero: $1961 ; 3)$ calificara como "sentencia de muerte para Nicaragua y una espada de Damocles para Centroamérica".

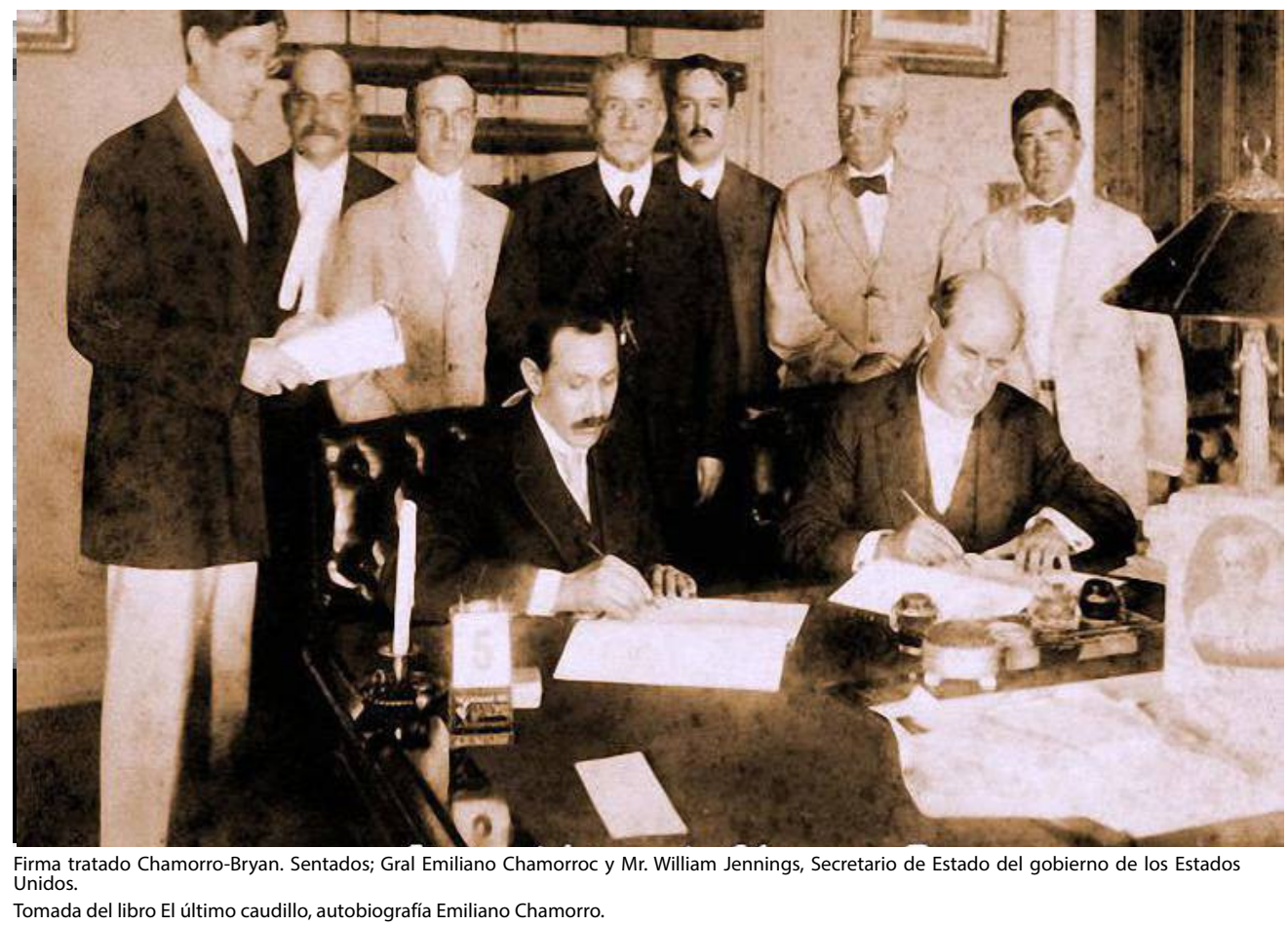

En este tratado el gobierno de Nicaragua cede a perpetuidad a los Estados Unidos toda la zona del Río San Juan y El Gran Lago para la construcción del canal interoceánico cuando el gobierno de ese país lo decida a cambio de solo 3 millones de dólares. El senado norteamericano se negó a apoyar ese tratado y lo anuló.

No conformes con esto la oligarquía de Nicaragua, logra que el 5 de agosto de 1914 el General Emiliano Chamorro, ministro plenipotenciario y enviado extraordinario de Nicaragua en los Estados Unidos, firmara con William Jennings Bryan, sucesor de Knox en el Departamento de Estado, un nuevo tratado, que no sólo 
reproducía el tratado anterior que había sido rechazado sino que concedía mucho más que aquel, pues dejaba a elección del gobierno norteamericano la construcción del canal, prerrogativa no otorgada en el tratado Weitzel - Chamorro.

Además de eso este tratado cedía por un lapso de noventa y nueve años, el derecho de establecer, explotar y mantener una base naval en el lugar del territorio de Nicaragua, sobre el golfo de Fonseca. Todo lo anterior siempre por los mismos 3 millones de dólares, los cuales serían utilizados para pagar parte de la deuda que se tenía con los banqueros estadounidenses, dicho de otro modo, el país estaba siendo vendido en su totalidad por 3 millones de dólares.

Desde 1912 a 1925 la vida económica, política y militar en Nicaragua era controlada por los estadounidenses a tal punto que dos terceras partes de las inversiones que incluían plantaciones de banano y café, exportaciones de madera y minería eran explotadas por los norteamericanos.

En 1925 llega al poder una coalición por medio del sufragio, Carlos Solórzano, conservador, como presidente y Juan Bautista Sacasa; liberal, como vicepresidente. Este mismo año se retiran las tropas yanquis y esto dio un aparente clima de tranquilidad política a Nicaragua. No obstante, Emiliano Chamorro, derrotado en las elecciones, se levanta contra el gobierno y se apodera del cuartel de Tiscapa, pretendiendo junto con Adolfo Díaz dar un golpe de Estado. Carlos Solórzano se subordinó a los golpistas y renuncia al cargo con el fin de recuperar el poder para su partido sin hacer alianzas con los liberales. De este modo el congreso designó a Emiliano Chamorro como presidente y este desterró al vicepresidente Sacasa.

Estados Unidos no aceptó al gobierno de Chamorro por cuestiones de política internacional, pues sería vergonzoso para ellos aceptar a un gobierno que naciera de golpes de Estado, al menos en esa época. El descontento de las fuerzas liberales por la hegemonía inconstitucional conservadora pone a Nicaragua al borde de una guerra civil que más tarde se llamaría "Guerra constitucionalista".

En 1927 el jefe militar José María Moncada comanda fuertes revueltas liberales que estuvieron a punto de entrar a Managua y Estados Unidos, al ver ese panorama peligroso para sus intereses obliga a Chamorro a dimitir y pone otra vez a Adolfo Díaz, quien al igual que en 1912, vuelve a solicitar la intervención militar estadounidense.

Las revueltas militares de Moncada continúan. Mientras tanto en las montañas de la Segovia se conformaba un ejército de campesinos, obreros, indígenas y trabajadores liberales liderados por Augusto César Sandino. El compromiso de este ejército es luchar por la Constitución y en contra de la intervención norteamericana. Sandino sostiene encuentros con Bautista Sacasa y Moncada, pero se decepciona cuando este último, en vez de atacar Managua negocia con Henry Stimpson, el enviado especial de los Estados Unidos y firma el 4 de mayo de 1927 el pacto del Espino Negro que puso fin a la lucha y entrega la soberanía patria a los marines.

(Mesa: 2010; 17) sostiene que este acto "demuestra que la lucha de Moncada no era ni patriota ni en defensa de los ideales del partido Liberal, sino una lucha que buscaba obtener beneficios personales". De hecho, Moncada se entrevistó con el diplomático gringo y como resultado se emitió una amnistía general y se convirtió en líder máximo de la política nicaragüense, aún por encima del mismo Juan Bautista Sacasa. 


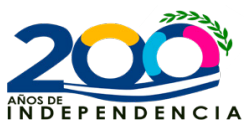

Después del pacto del Espino Negro que daba por terminada la guerra de manera oficial eran pocos los liberales deseosos de seguir combatiendo. Sin embargo, el 12 de mayo de 1927 Sandino le responde a Moncada que "no rendirá sus armas mientras los marines invasores permanezcan en Nicaragua". (Jaúregui: $2015 ; 10$ ) considera que por su actitud nacionalista y antiimperialista que lo mantenía en pie de lucha Sandino se fue quedando aislado, ya que todos los demás generales se aliaron con Moncada y muchos hombres desertaron.

No obstante, el impacto de la lucha desigual de Sandino contra los invasores gringos tuvo resonancia internacional y despertó en otros países sentimientos nacionalistas y antiimperialistas incluso en contra de la diplomacia del dólar, la cual se caracterizaba por sustituir las balas por dólares, pero en la práctica fue una política más agresiva que la del "Gran garrote".

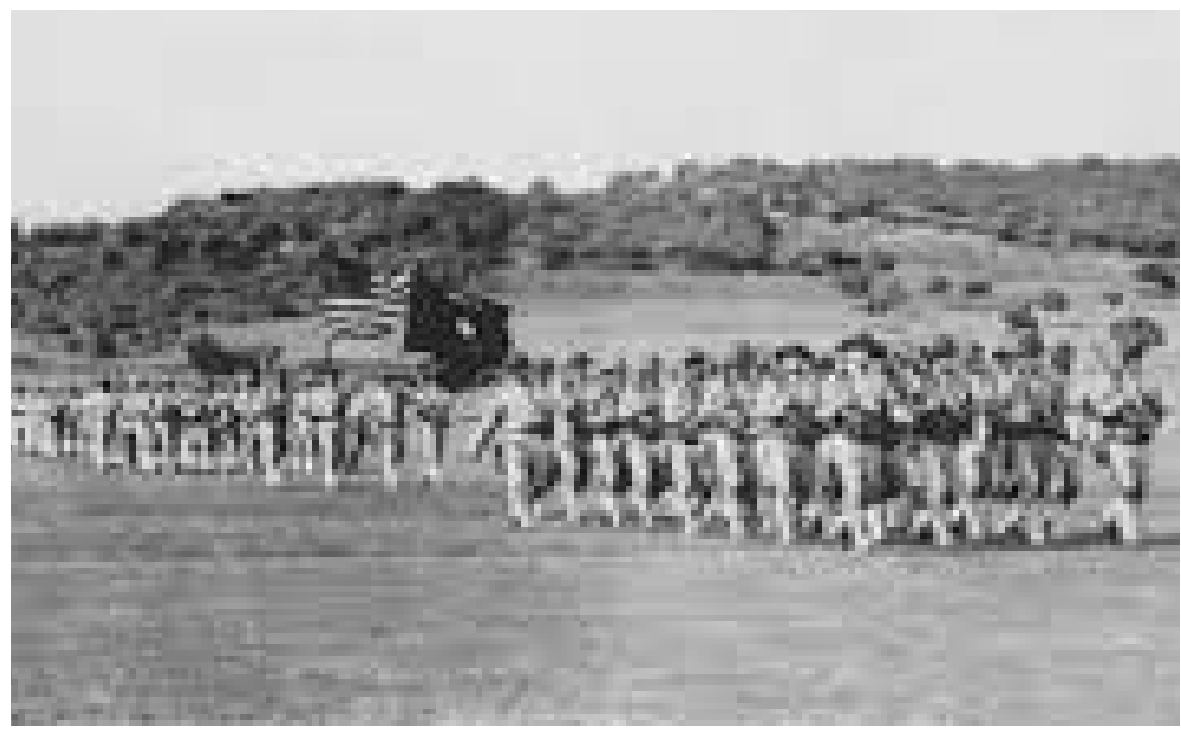

Tropas Norteamericanas en desfile militar en Managua.

Tomado de La lucha de liberación nacional en Nicaragua. (Archivo IHN)

Los intentos infructuosos de derrotar por la vía militar al ejército de Sandino y la preparación militar estadounidense a la naciente Guardia Nacional lograron que el gobierno norteamericano retirara a los marines de Nicaragua, a esto se suma la política del buen vecino, proclamada por el nuevo presidente de Estados Unidos, Franklin D. Roosevelt según la cual las intervenciones de los Estados Unidos eran asunto del pasado. En el pacto del Espino Negro Moncada acuerda con Stimpson la creación de una "constabularia" (Cuadrilla de alguaciles o Guardia civil) que sea eficiente, urbana y rural que se conocería como Guardia Nacional, la cual estuvo a las órdenes del mayor general del ejército norteamericano C. B. Matthews.

Si el gobierno de Estados Unidos estaba realmente decidido a retirar sus fuerzas militares de Nicaragua, por lo menos confiaba en poder resolver antes el problema que significaba la presencia de las guerrillas de Sandino en las montañas. Como es sabido, las tropas norteamericanas se empantanaron en esa guerra, sufriendo derrota tras derrota. Y comenzaron a manifestarse contradicciones dentro de Estados Unidos, donde surgieron distintos movimientos contra la intervención, hasta que la retirada se hizo inevitable, en 1933 , sin haber logrado aquel objetivo. 
Pero el retiro de los "marines" no significó el abandono de los intereses imperialistas en Nicaragua. Ahora quedaba la Guardia Nacional, ya bajo el mando del fiel pro norteamericano Anastasio Somoza García quien, como afirma (Lau: 2002; 14) "aprovechándose del cese de las acciones guerrilleras, en medio de las negociaciones para establecer las bases político-institucionales del país, asesinó a Sandino y dio un golpe de Estado". Se iniciaba así la era del somocismo en Nicaragua.

De esta forma los acuerdos de paz fueron sistemáticamente violados por la Guardia Nacional al frente de la cual ya se encontraba el General Anastasio Somoza García. Las permanentes violaciones y asesinatos de campesinos en las cooperativas del norte del país, obligaron a Sandino un año más tarde (febrero de 1934), a realizar otro viaje a Managua para reclamar el cumplimiento de los acuerdos de paz ante el Presidente Juan Bautista Sacasa.

Así pues, planificó el asesinato de Sandino en 1934 asestándole una emboscada por Loma de Tiscapa, separó el grupo que lo acompañaba, cerca de ahí fueron ejecutados y luego enterrados en una fosa común. Había sido una orden por parte del embajador estadounidense, Arthur Bliss Lane. Estrategia diseñada para presionar y destituir al Presidente Sacasa.

En el plano político internacional, la posguerra trajo desde Estados Unidos la concepción de la "guerra fría" y más tarde, con el triunfo de la revolución cubana, la contraofensiva imperialista con la estrategia de la "contrainsurgencia" y la Alianza para el Progreso. Somoza no desaprovechó ninguna oportunidad para postularse como el adalid del anticomunismo y convertirse en el principal aliado de Estados Unidos en la región.

Sin duda, el momento de apogeo para Somoza fue su apoyo, junto a la CIA norteamericana, a la invasión de Castillo Armas en Guatemala, que culminó con el derrocamiento del gobierno progresista de Jacobo Arbenz en 1954. De la misma manera, cuando se produjo algún intento revolucionario en Honduras o en Costa Rica, Somoza invadió con sus fuerzas en uno y otro lugar, demostrando que su poder iba más allá de las fronteras de Nicaragua.

Por esta vía, aparte de los efectos políticos internos, Somoza obtuvo mayor apoyo americano en armas y equipos militares, asesoramiento y entrenamiento de los cuadros de la Guardia Nacional, que le permitió modernizar su ejército y colocarlo a la altura de los mejores pertrechados y organizados de la región. Más allá de que el propio Somoza y su hijo fueron a estudiar a West Point, grupos de oficiales nicaragüenses comenzaron a asistir sistemáticamente a las nuevas escuelas montadas por Estados Unidos. La Guardia aumentó el número de sus efectivos y fue dividida en cuerpos especializados.

Más adelante, con la preparación de la invasión a Cuba, Estados Unidos montó una base militar en la costa atlántica de Nicaragua, desde donde salieron los barcos y aviones en dirección de la bahía de Cochinos. (Baccheta: 1985; 22) sostiene que "eso fue una demostración superior de la confianza de Estados Unidos en Somoza y de la fidelidad de éste a la causa del imperio. 


\section{Conclusiones}

Desde la fiebre del oro de 1849 hasta el retiro de las tropas de ocupación en 1933, Nicaragua tuvo que soportar la injerencia norteamericana a través de diplomáticos, banqueros y militares, la oligarquía nacional había pactado con los americanos puesto que tenían objetivos y preocupaciones. Por ejemplo, los primeros expansionistas norteamericanos empresarios de la Ruta del Tránsito como Cornelius Vanderbilt y filibusteros como William Walker - deseaban americanizar Nicaragua bajo la bandera del Destino Manifiesto. Vanderbilt enfatizó en el inculcar los valores económicos gringos en la sociedad nicaragüenses y, por último, Walker desató una "guerra racial" para colonizar Nicaragua con inmigrantes norteamericanos".

Por otro lado, la posición geográfica de Nicaragua ha sido paradójicamente ventaja y desventaja al mismo tiempo, pues sus facilidades naturales para la construcción de un Canal interoceánico propiciaron la intervención militar, política y económica de los Estados Unidos en este país hasta la Revolución Liberal de Zelaya, cuyo gobierno promovió un nacionalismo que les resultaba incómodo, lo que los llevó a aliarse con los conservadores para derrocar a Zelaya.La situación se puso más compleja a partir de 1912 porque la intervención estadounidense en Nicaragua se acrecentó a través de la imposición de gobiernos títeres, una ocupación militar y la usurpación del control de las finanzas lo cual devino en una justificada reacción de rebeldía centrada primero en la lucha de Benjamín Zeledón y después en la gesta anti intervencionista de Augusto César Sandino.

El asesinato de Sandino, planeado desde Estados Unidos y ejecutado por Somoza en 1934 significó el ascenso al poder de la dictadura somocista. Durante 40 años más Nicaragua estuvo bajo control de los Estados Unidos y su soberanía estaba otra vez comprometida, hasta que el pueblo mismo reaccionó y empezó una lucha insurreccional desde 1961 hasta la victoria popular que desemboca en la Revolución, el 19 de julio de 1979.

\section{Referencias bibliográficas.}

- $\quad$ Baccheta, V (1985) El desmoronamiento político de un ejército. La Guardia Nacional somocista. Revista Nueva Sociedad. Recuperado de https://static.nuso.org/media/articles/downloads/1347_1.pdf

- $\quad$ Barreto, N (2012) El expansionismo norteamericano. México: Seix - Barral.

- Bolaños, E (2007) La Revolución Liberal de Zelaya. Biblioteca digital Enrique Bolaños Geyer. Recuperado de https://www.enriquebolanos.org/data/docs/La\%20Revoluci\%C3\%B3n\%20liberal\%20 de\%20Zelaya.pdf

- Cajina, R (2010) Notas contra el intervencionismo estadounidense en Nicaragua. Revista Envío.

- Camacho, E. (1991). Los usos de Sandino. México: Ed. Nuestra América-UNAM

- Cánovas, G (2010) La intervención norteamericana en América Latina: Un duro golpe a la soberanía de nuestros pueblos. Universidad de Caracas. 
- Chamorro, A (2017) El poder del Estado y la intervención extranjera. Managua: UCA.

- $\quad$ Esgueva, A (2009) Las Constituciones políticas y sus reformas en la historia de Nicaragua, Managua, Editorial El Parlamento, Tomo I.

- Granados, L (1985) La campaña nacional contra el Filibusterismo. Managua: El parlamento.

- $\quad$ Guzmán, R (2005) Centroamérica y las grandes potencias: El Tratado Clyton - Bulwer de 1850. Revista de Temas Nicaraguenses.

- Jáuregui, G. (2015) Augusto César Sandino y la defensa de la Soberanía Nacional. 1926-1933. Revista GUARRACUCO. Universidad de Cundinamarca. Recuperado de http://revistas.unimeta.edu.co/ index.php/rc_es_guarracuco/article/view/288/503

- $\quad$ Lau, W (2002) Proceso de la Intervención norteamericana en Nicaragua. Managua: UCA. Recuperado de http://repositorio.uca.edu.ni/1654/1/Proceso\%20de\%20la\%20intervencion\%20 norteamericana\%20en\%20Nicaragua.pdf

- $\quad$ Navas- J et al. (2016). Los Estados Unidos: Un obstáculo histórico y sinuoso en la evolución de la integración centroamericana. Revista Iberoamericana De Bioeconomía Y Cambio Climático E-ISSN 2410-7980, 2(4), 528-548. https://doi.org/10.5377/ribcc.v2i4.5929

- $\quad$ Nieto, C. (1999). Los amos de la guerra y la guerra de los amos. Bogotá: Uniandes Cerec.

- $\quad$ Ramírez, S. (1983). El pensamiento vivo de Sandino. San José: Educa. Recuperado de http:// inncahis.uca.edu.ni/mc/uploads/media/el_Pensamiento_VivoT1ACS1981.pdf

- $\quad$ Rodríguez, M, (2014) “El Destino Manifiesto. El pensamiento expansionista de Alfred Thayer Mahan 1890-1914", Instituto de investigaciones Históricas, Universidad Michoacana de San Nicolás de Hidalgo.

- $\quad$ Romero, R. (1961). Sandino y los Yankis. México: Ediciones Patria y Libertad 